\title{
Effects of Fish Bone Meal Flour and Mineral Water «Abalakhskaya» on Bone Mineral Density
}

\author{
A. M. Palshina, PhD; S. L. Safonova, PhD; E. A. Emel'janova, PhD; \\ V. E. Borisov*; V. V. Epanov, PhD \\ M.K. Ammosov North-Eastern Federal University \\ Yakutsk, the Republic of Sakha (Yakutia), the Russian Federation
}

\begin{abstract}
We present the results of the complex application of fish bone meal flour (FBMF) and mineral water «Abalakhskaya» (AMW) for correction of calcium-phosphorus metabolism disorders in patients with abnormal bone mineral density (BMD) and biliary tract pathology. Significant improvement in the quality of life of patients in the postmenopausal period against the background of complex oral administration of FBMF and AMW was accompanied by a positive effect on BMD, and on the functional state of the biliary tract and intestine. (International Journal of Biomedicine. 2018;8(1):79-80.)
\end{abstract}

Key Words: fish bone meal flour $\bullet$ bone mineral density $\bullet$ calcium-phosphorus metabolism $\bullet$ osteopenia

\section{Introduction}

The high prevalence of the diseases of the musculoskeletal system and digestive system in the Republic of Sakha (Yakutia) (RS(Y)) requires the development of new technologies for health preservation, including the rational use of ecologically clean, biologically active natural resources available in the territory of $\mathrm{RS}(\mathrm{Y})$. The ichthyofauna of Yakutia is represented by 50 species belonging to 18 families.

The rivers and lakes of Yakutia are not only picturesque, but still virgin clean, transparent and full of fish. Every year, fishing companies of Yakutia catch about 5,000 tons of fish. The bone fraction from fish is still regarded as waste. However, fish bones are a high value by-product from the fish farm industry and due to the high calcium content this resource can conveniently be utilised as a high quality food ingredient or supplement. ${ }^{(1-3)}$ In the study by M.K. Malde and colleges, the calcium in enzymatically rinsed bones from Atlantic salmon and Atlantic cod was demonstrated to be a well absorbed source of $\mathrm{Ca}$ in young, healthy men. ${ }^{(4)}$

The purpose of the study was to study the effects of FBMF and AMW on BMD in patients with osteopenia and biliary tract pathology.

*Corresponding author: Vasiliy E. Borisov. M.K. Ammosov North-Eastern Federal University. Yakutsk, the Russian Federation. E-mail:vasborisov@yandex.ru

\section{Material and Methods}

The study protocol was reviewed and approved by the Ethics Committee of North-Eastern Federal University named after MK Ammosov (Protocol No. 9 of February 15, 2017). All participants provided the written informed consent.

We used FBMF from northern fish of the whitefish species, which is rich in macro- and microelements, in particular calcium and phosphorus, omega-3, and omega- 6 , as well as polyunsaturated fatty acids, proteins, fat and watersoluble vitamins to regulate calcium-phosphorus homeostasis in a complex with AMW (low-mineralized hydrogencarbonate sodium water with a slightly alkaline reaction). The duration of the course of treatment was 6 months (from March to August). The complex of therapeutic and preventive measures also included physical activity and educational programs for correcting overweight. ${ }^{(5)}$

Statistical analysis was performed using the statistical software «Statistica» (v6.0, StatSoft, USA). A probability value of $P<0.05$ was considered statistically significant.

\section{Results and Discussion}

The study included nine women volunteers of Yakut nationality, aged between 53 and 69 years (mean age: $62.9 \pm 4.9$ years). We determined the levels of ionized calcium in blood and daily urine, as well as $25(\mathrm{OH}) \mathrm{D}$ and phosphorus in the 
blood. BMD was measured using dual X-ray absorptiometry (DXA) by the GE Lunar iDXA Bone Densitometer in 3 standard projections (lumbar spine, femoral neck, forearm bone). According to the WHO criteria, osteopenia is defined as a BMD T-score between -1 and -2.5 standard deviations (SDs) below the healthy young adult norm, while osteoporosis is defined as a BMD T-score of -2.5SDs or lower. ${ }^{(6)}$

The assessment of blood pressure by Korotkov's method, ultrasound examination of the abdominal cavity, and esophagogastroduodenoscopy was performed on all patients.

At the beginning of the study, patients complained of pains in the knee and hip joints, in the lumbar spine during the prolonged static load, bitterness in the mouth, bloating, pain in the right hypochondrium, and unstable stools when taking fatty, fried foods. All of them had chronic acalculous cholecystitis and focal atrophic gastritis, and were under medical supervision.

After the course of complex intake of FBMF and AMW, patients reported an improvement in their overall health, normalization of the stool, a reduction of pain in the joints and lumbar spine, an increase in physical activity, an improvement in the condition of the nail plates and hair.

There was a tendency toward in a decrease in the level of ionized blood calcium from $1.23 \pm 0.05 \mathrm{mmol} / 1$ to $1.16 \pm 0.02$ $\mathrm{mmol} / \mathrm{l}$ and daily urinary calcium excretion from $5.65 \pm 2.62$ $\mathrm{mmol} /$ day to $4.76 \pm 2.2 \mathrm{mmol} /$ day after the course of complex intervention. We found an increase in blood level of $25(\mathrm{OH}) \mathrm{D}$ from $23.7 \pm 5.29 \mathrm{~g} / \mathrm{ml}$ to $28.01 \pm 5.29 \mathrm{~g} / \mathrm{ml}(P<0.05)$.

According to DXA, the average increase in BMD was $3.36 \%\left(0.03 \mathrm{~g} / \mathrm{cm}^{2}\right)$, and the increase in the $\mathrm{T}$ - and Z-scores was $0.3 \mathrm{SD}(P<0.05)$.

Postmenopausal osteoporosis is one of the most important problems of modern health care because of the high prevalence and severity of fractures arising from minor injuries. Cafortified foods are likely to play an important role in helping consumers to meet the calcium requirements needed to reduce the risk of osteoporosis. Significant improvement in the quality of life of patients in the postmenopausal period against the background of complex oral administration of FBMF and AMW was accompanied by a positive effect on BMD, and on the functional state of the biliary tract and intestine. The results obtained require further study of the effects of the combined use of FBMF and AMW.

\section{Competing interests}

The authors declare that they have no competing interests.

\section{Sources of Funding}

The study was supported by the Grant of the Head of the Republic of Sakha (Yakutia) for young scientists, specialists and students.

\section{References}

1. Jung WK, Lee BJ, Kim SK. Fish-bone peptide increases calcium solubility and bioavailability in ovariectomised rats. Br J Nutr. 2006;95(1):124-8.

2. Malde MK, Graff IE, Siljander-Rasi H, Venäläinen E, Julshamn K, Pedersen JI, Valaja J. Fish bones -- a highly available calcium source for growing pigs. J Anim Physiol Anim Nutr (Berl). 2010;94(5):e66-76. doi: 10.1111/j.14390396.2009.00979.x.

3. Toppe J, Albrektsen S, Hope B, Aksnes A. Chemical composition, mineral content and amino acid and lipid profiles in bones from various fish species. Comp Biochem Physiol B Biochem Mol Biol. 2007;146(3):395-401.

4. Malde MK, Bügel S, Kristensen M, Malde K, Graff IE, Pedersen JI. Calcium from salmon and cod bone is well absorbed in young healthy men: a double-blinded randomised crossover design. Nutr Metab (Lond). 2010;7:61. doi: 10.1186/1743-7075-7-61.

5. Palshina AM, Safonova SL, Emel'janova EA, Borisov VE, Epanov VV. [Experience of a non-medicamentous correction of calcium-phosphoric metabolism disorder in a patient with comorbid pathology]. Yakut Medical Journal. 2017;60(4):101-103. [Article in Russian].

6. Assessment of fracture risk and its application to screening for postmenopausal osteoporosis. Report of a WHO Study Group. Geneva, World Health Organization, 1994 (WHO Technical Report Series, No. 843). 